\title{
Vantagens e desvantagens no processo de intercooperação: uma análise da relação entre uma cooperativa central e uma cooperativa singular
}

\section{Challenges and perspectives for intercooperation: an analysis of the relationship between a central cooperative and a single cooperative}

\begin{abstract}
Resumo
A intercooperação pode ser considerada como um passo avançado do cooperativismo, uma vez que, uma cooperativa singular, quando associada a uma cooperativa central, demonstra como é possível cooperar com outras cooperativas para construir soluções estratégicas. Para este estudo, foram analisadas duas cooperativas agrícolas que encontram-se em uma relação de intercooperação. Juntas no exercício de 2018, empregaram mais de 16 mil colaboradores diretos e movimentaram, em termos de faturamento, aproximadamente 9 bilhões de reais, segundo seus relatórios gerenciais. Sendo assim, o presente estudo toma como objetivo compreender o processo de intercooperação entre uma cooperativa central e uma de suas associadas, descrevendo os benefícios, desafios e perspectivas envolvidos nesse processo. Para tanto, foram entrevistados dois executivos, um de cada cooperativa, e, os dados foram analisados qualitativamente por análise de conteúdo segundo os fatores dispostos no framework de Poyatos, Gámez e Hernández (2010). Os resultados indicam para uma relação virtuosa, com dificuldades relativas ao ambiente institucional, políticas de preços e tomada de decisão. Em linhas gerais o estudo confirma os achados de Poyatos, Gámez e Hernández (2010), com exceção para o fator que tangencia a qualificação dos gestores. Dentre outros achados, destaca-se o fortalecimento do espírito cooperativo, a competitividade e o desenvolvimento da região atendida pela cooperativa.
\end{abstract}

Palavras-chave: intercooperação, cooperativismo, competitividade.

\begin{abstract}
Intercooperation can be considered as an advanced step of cooperativism, since a single cooperative, when associated with a central cooperative, demonstrates how it is possible to cooperate with other cooperatives to build strategic solutions. For this study, two agricultural cooperatives that are in an intercooperation relationship were analyzed. In general terms, the two cooperatives together employed, in 2018, more than 16 thousand direct employees and, in terms of turnover, approximately 9 billion reais, according to their management reports. Thus, this study aims to understand the process of intercooperation between a central cooperative and one of its associates, describing the benefits, challenges and perspectives involved in this process. For this, two executives were interviewed, one from each cooperative, and the data were qualitatively analyzed by content analysis according to the factors arranged in the framework of Poyatos, Gámez and Hernández (2010). The results indicate a virtuous relationship, with difficulties related to the institutional environment, pricing policies and decision making. In general, the study confirms the findings of Poyatos, Gámez and Hernández (2010), except for the factor that affects the qualification of managers. Other findings include strengthening the cooperative spirit, competitiveness and development of the region served by the cooperative.
\end{abstract}

Keywords: intercooperation, cooperativism, competitiveness.

Elizane Maria de Siqueira Wilhelm ${ }^{\mathrm{I}}$, Humberto Reis Santos-Souza ${ }^{\mathrm{II}}$

I Universidade Tecnológica Federal do Paraná. Paraná, PR. elizanew@utfpr.edu.br

II Instituto Federal de Educação, Ciência e Tecnologia do Rio de Janeiro. Rio de Janeiro, RJ. humberto.souza@ifrj.edu.br 


\section{Introdução}

A intercooperação mostra-se como um fenômeno relevante para que seja possível compreender as relações e os processos interorganizacionais, bem como, as relações de competitividade que uma organização, que preza pelos princípios cooperativos, demonstra em um ambiente que apresenta cada vez mais rivalidade entre os concorrentes, especialmente, quando trata-se de cadeias alimentícias globais altamente estruturadas (LAGO; SILVA, 2012).

Embora a vantagem competitiva tenha seu espaço delineado no mainstream da administração, há indícios de que a cooperação, processos de integração, arranjos interfirmas, consórcios, processos modulares, coopetição e outras relações interorganizacionais tenham apresentado relativa importância no campo da pesquisa. Cabe destacar, também, que a relação virtuosa entre cooperativas centrais e suas singulares é destacada por outras pesquisas (GIMENES; GIMENES, 2007; LIMA; CARVALHO, 2012; CARPES et al., 2013; KONZEN; OLIVEIRA, 2015; THAMER; LAZZARINI, 2015; BORGES; DOMINGUES, 2017; DAL-SOTO; MONTICELLI, 2017; HENRIQUES; MIGUEL, 2017).

Além disso, a intercooperação pode apresentar-se como estratégia para o desenvolvimento sustentável , uma vez que, integra associados e executivos, proporcionando um intercâmbio de soluções e troca de conhecimento, além de propiciar o acesso a diferentes e amplos mercados permitindo que o produtor rural diversifique sua atividade e permaneça no campo e associado a cooperativa (LAGO; SILVA, 2012; PERONI; PEGLOW; KOHLER, 2018).

Nesse sentido, a intercooperação pode ser considerada como um passo avançado do cooperativismo, uma vez que, uma cooperativa singular, quando associada a uma cooperativa central, demonstra como é possível cooperar com outras cooperativas para construir soluções estratégicas e sustentáveis. Essas soluções, por sua vez, têm a potencialidade de proporcionar maior competitividade à cooperativa central e suas singulares, podendo proporcionar mais desenvolvimento para a região onde atua (BORGES; DOMINGUES, 2017; OCB, 2018).

Em termos de volume de negócios, as cooperativas agroindustriais representam mais de um milhão de associados, congregados em mais de 1600 cooperativas, gerando quase 200 mil empregos diretos. Desse modo, segundo o Ministério da Agricultura (2018), o cooperativismo é responsável por mais de $50 \%$ do PIB (Produto Interno Bruto) agrícola e que cerca de $48 \%$ do que é produzido no campo brasileiro passa por uma cooperativa.

Nesse sentido, a relação entre duas cooperativas agroindustriais, uma singular e uma central, localizadas no oeste do estado do Paraná, é objeto deste estudo. Em termos gerais, as duas cooperativas juntas empregaram, no exercício de 2018, 17.939 colaboradores diretos e movimentaram, em termos de faturamento, $\mathrm{R} \$ 9,305$ bilhões de reais, segundo seus relatórios gerenciais. Cabe destacar também que a cooperativa singular operou no ano de 2018 com 10887 associados.

Diante dessa conjuntura e compreendendo a potencialidade que a intercooperação pode oferecer à economia brasileira, emerge o seguinte problema de pesquisa: quais os benefícios, desafios e perspectivas oferecidos pelo processo de intercooperação? Para respondê-lo, o presente estudo toma como objetivo compreender em que se constituem as vantagens e desvantagens da intercooperação entre uma cooperativa central e singular.

Para tanto, este trabalho está organizado a partir dessa introdução, seguida da fundamentação teórica disposta em dois eixos: cooperativismo e intercooperação. Na sequência, o método de pesquisa é detalhado, seguido da apresentação e análises dos resultados. Por fim, apresentam-se algumas considerações finais. 


\section{Fundamentação teórica}

Como salientado na introdução a intercooperação figura-se como importante fator para o desenvolvimento e a competitividade em cooperativas singulares. Dessa maneira, para abordar o fenômeno, esta fundamentação teórica parte do conceito de cooperativismo e suas implicações. Na sequência abordam-se a intercooperação, bem como, suas vantagens e desvantagens.

\subsection{Cooperativismo}

Segundo a Organização das Cooperativas Brasileiras - OCB (2018), o cooperativismo pode ser definido como uma filosofia de cujo objetivo é transformar o mundo em um lugar mais justo, feliz, equilibrado e com melhores oportunidades para todos, tendo ainda, como preceito, propiciar o desenvolvimento econômico e desenvolvimento social, produtividade e sustentabilidade.

Nesse contexto, o cooperativismo está presente em mais de 100 países, congregando um bilhão de pessoas e gerando cerca de 250 milhões de empregos, em um total de 2,6 milhões de cooperativas. O cooperativismo também apresenta uma relação virtuosa para manter o homem no campo, bem como, na manutenção dos compromissos com a sustentabilidade ambiental e social (SILVA; LEISMANN, 2016; OCB, 2018).

Como características, pode-se observar que uma cooperativa tenha, como um de seus principais objetivos, a distribuição de sobras (resultados econômicos) ao final do exercício em forma de dinheiro, o que, por sua vez, fortalece os aspectos de confiança e transparência a respeito do comportamento econômico da organização cooperativista. Por outro aspecto, a cooperativa pode distribuir os resultados econômicos em forma de melhores preços para a compra de insumos e/ou equipamentos agrícolas, assistência técnica, prestação de serviços, dentre outros. Ainda assim, uma cooperativa pode distribuir as sobras e, concomitantemente, prestar apoio aos seus cooperados (BIALOSKORSKI NETO, 2007).

O cooperativismo é regido usualmente por sete princípios norteadores. (1) A adesão livre e voluntária é o princípio que demonstra a abertura da cooperativa para qualquer associado, sem nenhuma discriminação. (2) A gestão democrática caracteriza-se como outro princípio, capaz de permitir que a cooperativa possa ser gerida pelos seus membros por meio de um sistema democrático. (3) A participação econômica dos membros garante que as contribuições tenham relação equitativa nos compromissos da cooperativa, bem como, na divisão de sobras. (4) Autonomia e independência é um princípio do cooperativismo que permite a autonomia administrativa da cooperativa, independente dos acordos e parcerias firmados. (5) O princípio da educação, formação e informação visa promover a capacitação e a formação continuada de membros e colaboradores para o desenvolvimento do sistema cooperativo e da sociedade. (6) A intercooperação também apresentase como um princípio cooperativo e consiste na cooperação entre cooperativas. (7) O interesse pela comunidade também figura-se como importante princípio, pois, visa o desenvolvimento sustentável da comunidade (BIALOSKORSKI NETO, 2004; FORCADELL, 2005; OCB, 2018).

Esses princípios desempenham um papel importante para a manutenção do espírito cooperativista, visto que, a partir deles é possível que a cooperativa possa tornar-se um centro de apoio técnico/logístico/financeiro, proporcionando um espaço onde a cooperação permita o desenvolvimento do negócio. Especialmente para as cooperativas agroalimentares, os desafios para o desenvolvimento e manutenção do negócio se tornam cada vez mais pesados, uma vez que, a competição ocorre com players de escala mundial e com desenvolvidas cadeias multinacionais (BIALOSKORSKI NETO, 2007; LAGO; SILVA, 2012; BORGES; DOMINGUES, 2017; MATEOSRONCO; GUZMÁN-ASUNCIÓN, 2018; PERONI; PEGLOW; KOHLER, 2018). 
De fato, percebe-se que a cooperativa precisa atender os interesses financeiros dos stakeholders, bem como, contribuir para o desenvolvimento rural e territorial. Isso significa contribuir para a geração de emprego, renda e oportunidades para seus associados e para os envolvidos no processo (ALFONSO; CUMPLIDO; GONZALEZ, 2o16; MATEOS-RONCO; GUZMÁNASUNCIÓN, 2018; SALVADOR; SANZ; CASTEL, 2018).

\subsection{Intercooperação}

A intercooperação, sexto dos sete princípios do cooperativismo, pode ser definida como o processo de integração pelo qual cooperativas cooperam entre si em estruturas locais, regionais, nacionais e/ou internacionais, com fulcro no bem comum (BIALOSKORSKI NETO, 2004; POYATOS; GÁMEZ; HERNÁNDEZ, 2010; LAGO; SILVA, 2012; OCB, 2018).

Diante de um mercado altamente competitivo e dominado por superestruturas, tem-se na intercooperação a oportunidade de tornar-se mais competitivo frente ao ambiente altamente complexo e em constante mudança. Nesse processo destacam-se os que ocorrem em cooperativas agroindustriais, proporcionando desenvolvimento econômico para determinadas regiões, a permanência do homem no campo e a diversificação de atividades nas propriedades rurais associadas às cooperativas singulares (GIMENES; GIMENES, 2007; LAGO; SILVA, 2012; BORGES; DOMINGUES, 2017; SERAMIM; MIURA, 2018).

O processo de intercooperação ocorre quando cooperativas singulares juntam-se por interesses ou estratégias em comum ou quando há a necessidade de unir competências para a manutenção do espaço no mercado ou para a conquista de novos mercados, especialmente quando, sozinha, uma cooperativa singular teria muitos desafios para posicionar-se no ambiente (KONZEN; OLIVEIRA, 2015; BORGES; DOMINGUES, 2017).

Os aspectos de volume, padronização, escalam, aquisição de tecnologia e mobilização de competências, quando dentro do processo de intercooperação, ganha sinergia e o modelo tem a potencialidade de entregar mais valor do que as partes poderiam entregar quando separadas (BIALOSKORSKI NETO, 2004; KONZEN; OLIVEIRA, 2015).

Além de ser um dos princípios do cooperativismo, a intercooperação é considerada uma evolução do espírito de colaboração organizacional, uma vez que de forma conjunta as cooperativas fortalecem o movimento e apoiam os cooperados de maneira mais efetiva (KONZEN; OLIVEIRA, 2015; OCB, 2018).

Em tratando-se de volume, os custos de transação também podem ser afetados, propiciando que a cooperativa central possa usufruir de políticas públicas, por exemplo. Nesse sentido, as próprias relações entre as cooperativas singulares podem ser facilitadas para a formação de redes ou coalizões de interesses (BIALOSKORSKI NETO, 2004; POYATOS; GÁMEZ; HERNÁNDEZ, 2010).

Ainda assim, algumas características podem ser observadas como resultados esperados no processo de intercooperação, tais como: ganhos na escala, aumento do valor agregado, acesso a mercados e informações, maior rentabilidade aos associados, novas opções de rendimento e melhoria nas condições sociais (LAGO; SILVA, 2012).

O estudo de Lago e Silva (2012) apresentam alguns fatores condicionantes para o processo de intercooperação. Dentre eles destaca-se, por exemplo, a confiança que deve estar presente nos arranjos institucionais entre as cooperativas, o que, também, fortalece os relacionamentos. Além disso, o processo ocorre permeado pelo contexto de um projeto a ser construído pelas partes, o que exige o comprometimento. Destacam-se também as relações de liderança que, traduzida em planos estratégicos, manifesta-se nos objetivos de longo prazo (para onde iremos). 
Os autores afirmam ainda que para que ocorra a intercooperação é necessária especial atenção a aspectos como: a) o ambiente, o qual necessita de controles específicos para dimensionar as ações que devem ser tomadas; b) as compensações, pois ocupam outro papel crucial para o desenvolvimento de relações em forma de intercooperação, uma ver que a cooperativa singular precisa visualizar seus esforços sendo compensados; e c) a comunicação, fator chave para o processo, porque, evita ruídos e posteriores problemas entre as cooperativas.

No mesmo estudo, destacam-se também o comprometimento, a interdependência, a transparência, a gestão profissional, a clareza das doutrinas e o controle das vaidades como condicionantes para que a cooperação entre cooperativas ocorra.

Alguns desafios que podem impedir ou dificultar a intercooperação também podem ser observados no medo das cooperativas perderem sua autonomia no processo de tomada de decisão, nas diferenças culturais entre as organizações, na falta de confiança, no excesso de competição entre as cooperativas associadas, nas políticas de preços; nas disputas por poder, em gestores com capacitação insuficiente, em processo de tomada de decisão mais complexo em que pode ocorrer a perda de poder, na democracia delegada, pois, o associado à cooperativa singular não toma decisões diretas relativas aos processos de gestão da cooperativa central e na conscientização dos associados sobre o funcionamento desta parceria (BIALOSKORSKI NETO, 2004; POYATOS; GÁMEZ; HERNÁNDEZ, 2010; LAGO; SILVA, 2012; KONZEN; OLIVEIRA, 2015; MATEOS-RONCO; GUZMÁNASUNCIÓN, 2018).

Em outro panorama, o estudo de Borges e Domingues (2017) mostrou que algumas cooperativas aumentaram significativamente sua capacidade produtiva e força de trabalho, bem como, apresentaram crescimento interno com inserção em outros negócios com base na intercooperação para a criação de novas unidades industriais e parcerias com outras empresas. Isso proporcionou, por sua vez, a diluição dos riscos, custos e benefícios oriundos dos projetos em que essas empresas adentraram. Assim, esses fatores associados parecem indicar que esta soma de esforços pode ser uma alternativa para o crescimento e estabilidade da organização.

O estudo de Mendes (2017), ao analisar três cooperativas do setor agrícola no estado do Paraná, quanto a influência da intercooperação no desempenho econômico e financeiro, verificou que existe uma relação positiva entre esta relação e os resultados econômicos e financeiros, especialmente atrelados à geração de valor para as cooperativas envolvidas no que tange ao ganho de escala e ao desenvolvimento de marcas próprias.

Na mesma tônica, o estudo de Poyatos, Gámes e Hernándes (2010), realizado junto as cooperativas da região de Andalucia na Espanha, analisou as particularidades da intercooperação como instrumentos de cooperação entre cooperativas, abordando as vantagens e desvantagens enfrentadas pelas cooperativas que estão inseridas nesse processo de integração.

As principais vantagens do processo de intercooperação, descritas por Poyatos, Gámes e Hernándes (2010), estão relacionadas com o fortalecimento do espírito cooperativo, como o nível de participação relativo da cooperativa central na cooperativa singular, aos benefícios provenientes dos processo de gestão, de produção e comercialização e a possibilidade de redução de custos por meio de processo de gestão que estão concentrados na cooperativa central. O compilado é apoiado por outros estudos similares (BIALOSKORSKI NETO, 2004; LAGO; SILVA, 2012; KONZEN; OLIVEIRA, 2015; MENDINA, 2015; MENDINA et al., 2016; BORGES; DOMINGUES, 2017; MENDES, 2017; SOUZA et al., 2017; MATEOS-RONCO; GUZMÁN-ASUNCIÓN, 2018). O compilado das vantagens desse processo está descrito na Figura 1.

Os autores Poyatos, Gámez e Hernández (2010) também apresentam as principais desvantagens do processo. Elas estão relacionadas com certa medida de perca da autonomia na tomada de decisão, a democracia delegada, a falta de pessoal qualificado para ocupar cargos de 
gestão e a conscientização por parte dos associados no que se refere ao processo de intercooperação. Esses fatores limitantes encontrados na pesquisa dos autores também estão presentes na literatura sobre o tema (BIALOSKORSKI NETO, 2004; 2007; LAGO; SILVA, 2012; MENDINA, 2015; MENDINA et al., 2016; MENDES, 2017; SOUZA et al., 2017; MATEOS-RONCO; GUZMÁN-ASUNCIÓN, 2018; SERAMIM; MIURA, 2018). O compilado das desvantagens desse processo está descrito na Figura 1.

Figura 1 - Vantagens e Desvantagens Relativas ao Processo de Intercooperação

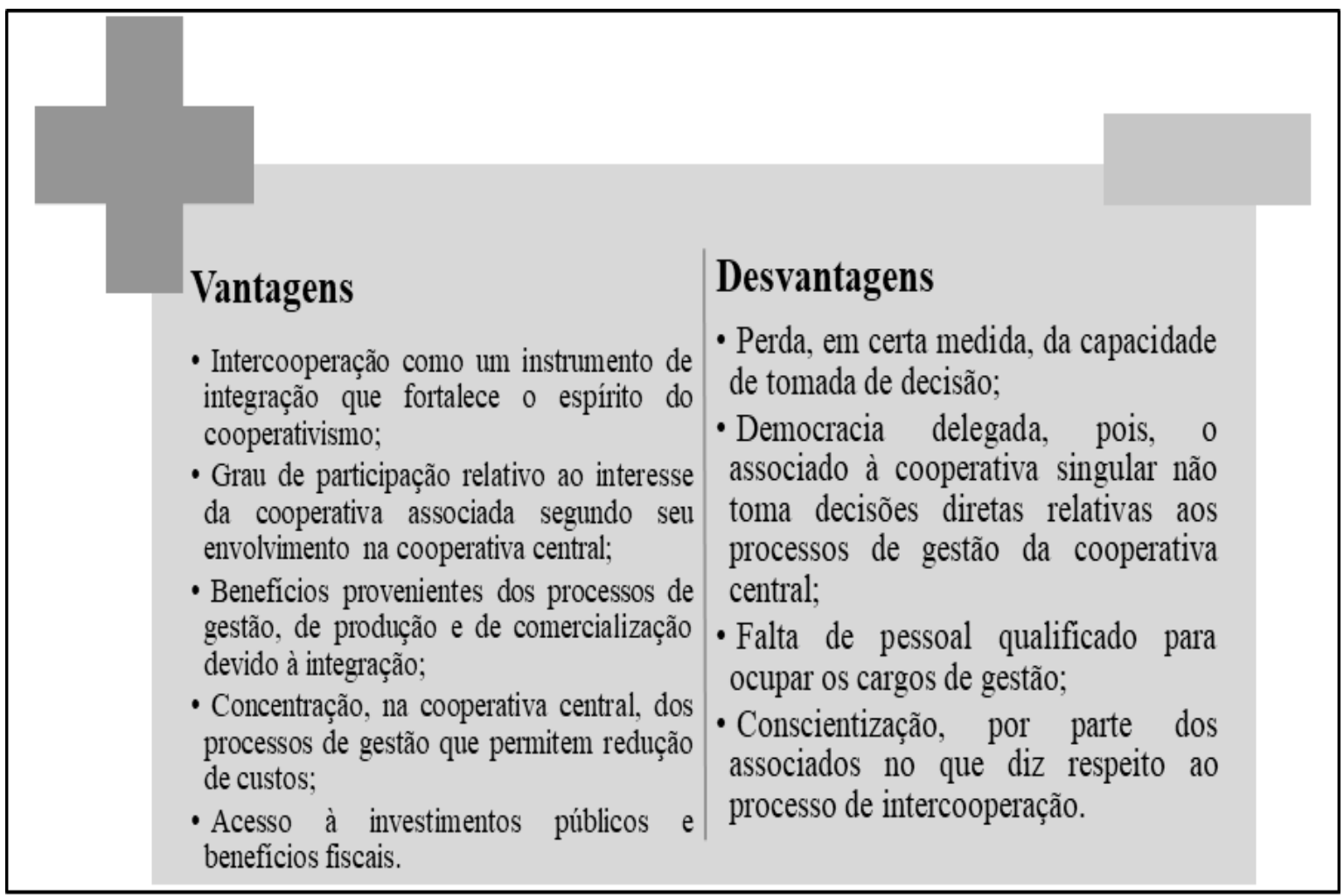

Fonte: elaborado pelos autores com base em Poyatos, Gámez e Hernández (2010, p. 108-110).

\section{Método}

A presente pesquisa caracteriza-se como qualitativa quanto a forma de análise e abordagem do problema. A pesquisa qualitativa foi escolhida para este estudo, pois, caracteriza-se como "um conjunto de técnicas interpretativas que procuram descrever, decodificar, traduzir e, desta forma, apreender o significado, e não a frequência, de certos fenômenos ocorrendo de forma mais ou menos natural no mundo social" (COOPER; SCHINDLER, 2011, p. 189), sendo que, para este estudo, o fenômeno em investigação trata-se da intercooperação, mais especificamente a relação entre uma cooperativa central e uma de suas cooperativas singulares.

Quanto aos objetivos, este estudo caracteriza-se como exploratório por aproximar-se do fenômeno no intuito de proporcionar uma visão geral (SILVA; MENEZES, 2005; GIL, 2008). Em tratando-se dos procedimentos técnicos, a pesquisa documental ocupou-se de realizar um levantamento sobre o processo de intercooperação com base nos documentos institucionais (relatórios de gestão, informes, notícias, etc.) disponíveis nos sítios eletrônicos das cooperativas.

Ao mesmo tempo, o roteiro de entrevista foi construído com base nos achados de Poyatos, Gámez e Hernández (2010), ao abordarem as principais vantagens e desvantagens do processo. O levantamento de opinião foi a técnica utilizada para entrevistar um executivo da cooperativa central e um executivo da cooperativa singular. As entrevistas foram gravadas em equipamento $\mathrm{MP}_{3}$ e, posteriormente, transcritas na íntegra totalizando 42 páginas. Para preservar o anonimato os nomes 
das cooperativas foram suprimidos e, quando referidas, tratam-se de cooperativa central e cooperativa singular com seus respectivos executivos.

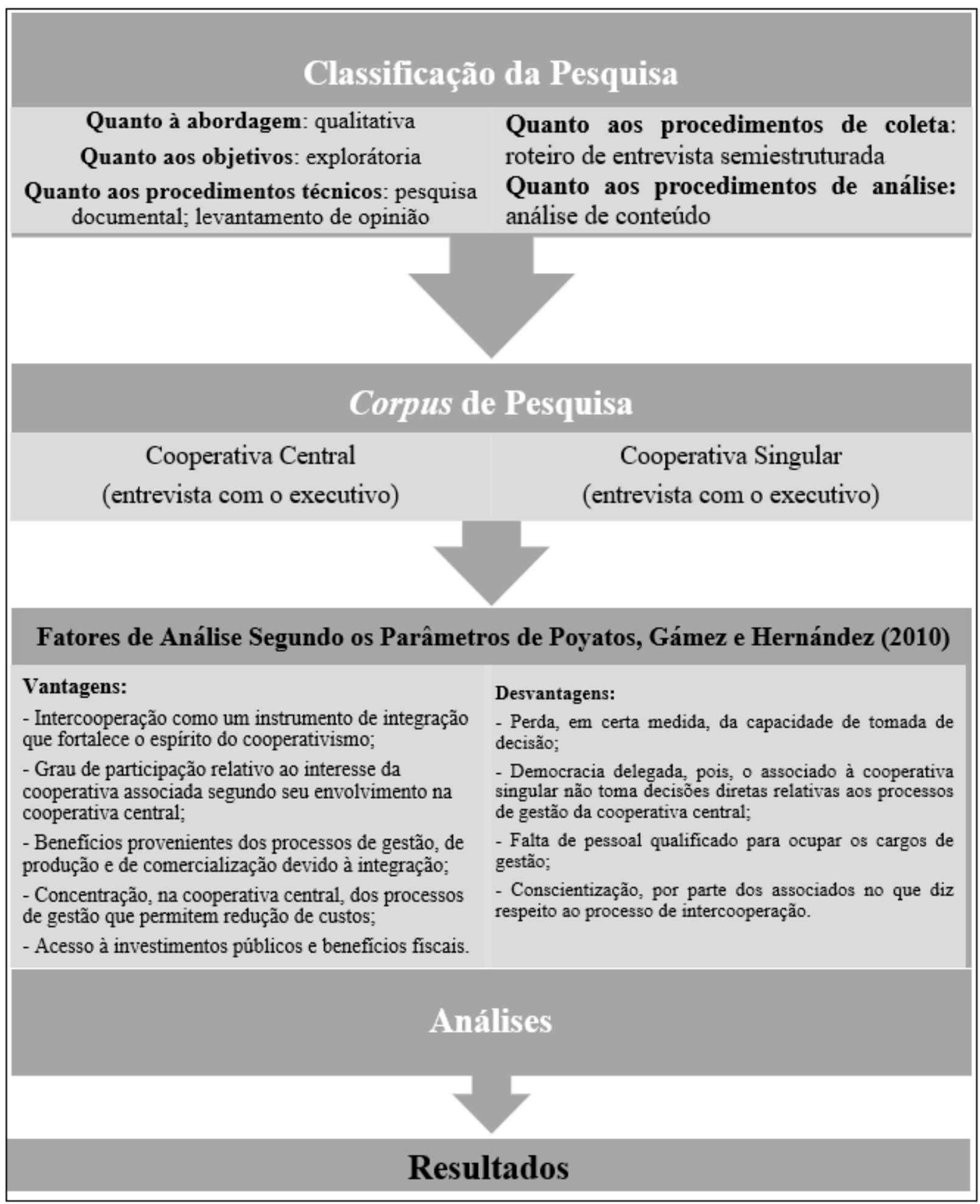

Fonte: elaborado pelos autores com base em Poyatos, Gámez e Hernández (2010, p. 108-110).

O exame dos dados utilizou a análise de conteúdo com o auxílio do software Atlas.TI. A análise de conteúdo foi escolhida como técnica de diagnóstico por admitir a categorização lógica das comunicações permitindo a depreensão dos sentidos seguindo os preceitos previamente estabelecidos (BARDIN, 2016). Para a categorização das comunicações utilizou-se, novamente, o 
framework proposto por Poyatos, Gámez e Hernández (2010) que pondera aspectos relativos ao funcionamento e intercorrências do processo de intercooperação. Em complemento, a análise do discurso também foi utilizada para complementar o processo de depreensão dos sentidos (BARDIN, 2016).

A partir desse framework, as comunicações foram analisadas e categorizadas, permitindo a extração dos sentidos, pautadas na estrutura do método anteriormente detalhada (Figura 2). À luz da literatura doravante apresentada, segue-se a análise e discussão dos achados na pesquisa.

\section{Análise e discussão}

A cooperativa central em estudo destaca-se no cenário nacional entre as 300 maiores empresas do país, composta por cinco cooperativas singulares, com um faturamento de R\$2,92 bilhões e mais de 8.000 colaboradores diretos. No exercício de 2018 a empresa cresceu 3,31\%, com resultado líquido de R $\$ 65,5$ milhões. Ao total foram abatidos no mesmo exercício 2.227.026 cabeças de suínos e processados 222.804.143 litros de leite.

Na mesma tônica de crescimento, a cooperativa singular alcançou em 2018 um faturamento na marca de $\mathrm{R} \$ 6,3$ bilhões, registrando um aumento de $26,02 \%$ sobre o exercício anterior e empregou no período 9.847 colaboradores. Entregou para a cooperativa central um total de 560.091 cabeças de suínos para abate, totalizando $25,14 \%$ das cabeças abatidas pela cooperativa central. Além dos suínos, a cooperativa singular produziu e entregou à cooperativa central 25.905.684 litros de leite. Os resultados, em termos de faturamento bruto, na área bovinocultura de leite e suinocultura associadas a cooperativa central representaram em conjunto $4,3 \%$ do faturamento da cooperativa singular para o mesmo período. As cotas da cooperativa singular na cooperativa central representam $24,43 \%$ do capital social.

Esses dados corroboram com os achados de Borges e Domingues (2017), Mendes (2017), Mendina (2015) e Konzen e Oliveira (2015) ao indicarem uma relação virtuosa na diversificação do risco, complementação do faturamento, geração de mais valor do que quando separadas. Assim, a partir dos relatórios gerenciais, há indícios de que a participação da cooperativa singular na cooperativa central permitiu o ganho de escala, uma vez que, as atividades de bovinocultura de leite e a suinocultura teriam bem menos participação no mercado e sofreriam ainda mais os efeitos da competitividade se não associados a cooperativa central. Por outro lado, percebe-se que a cooperativa central tem, na sua relação com a cooperativa singular, a necessidade de matéria prima para o abate e processamento de boa parte de sua produção em uma cadeia contratualmente garantida, dada a porcentagem de participação da singular nesse quesito (MATEOS-RONCO; GUZMÁN-ASUNCIÓN, 2018; PERONI; PEGLOW; KOHLER, 2018).

Diante da natureza dos negócios e da complexidade das relações interorganizacionais propostas pela intercooperação, a análise dos dados das entrevistas apresenta algumas das características propostas por Poyatos, Gámez e Hernández (2010) no que tange às vantagens e desvantagens do processo. Essas características foram previamente abordadas na fundamentação teórica. Os fatores estabelecidos para a análise de conteúdo foram apresentados na Figura 2.

Para facilitar a visualização, os fatores associados aos achados de Poyatos, Gámez e Hernández (2010) e os fatores emergentes da análise, bem como, suas respectivas frequências são apresentados na Figura 3. Sendo assim, os principais achados na análise de conteúdo são articulados com a teoria. 
Figura 3 - Frequência das Respostas por Fatores de Análise

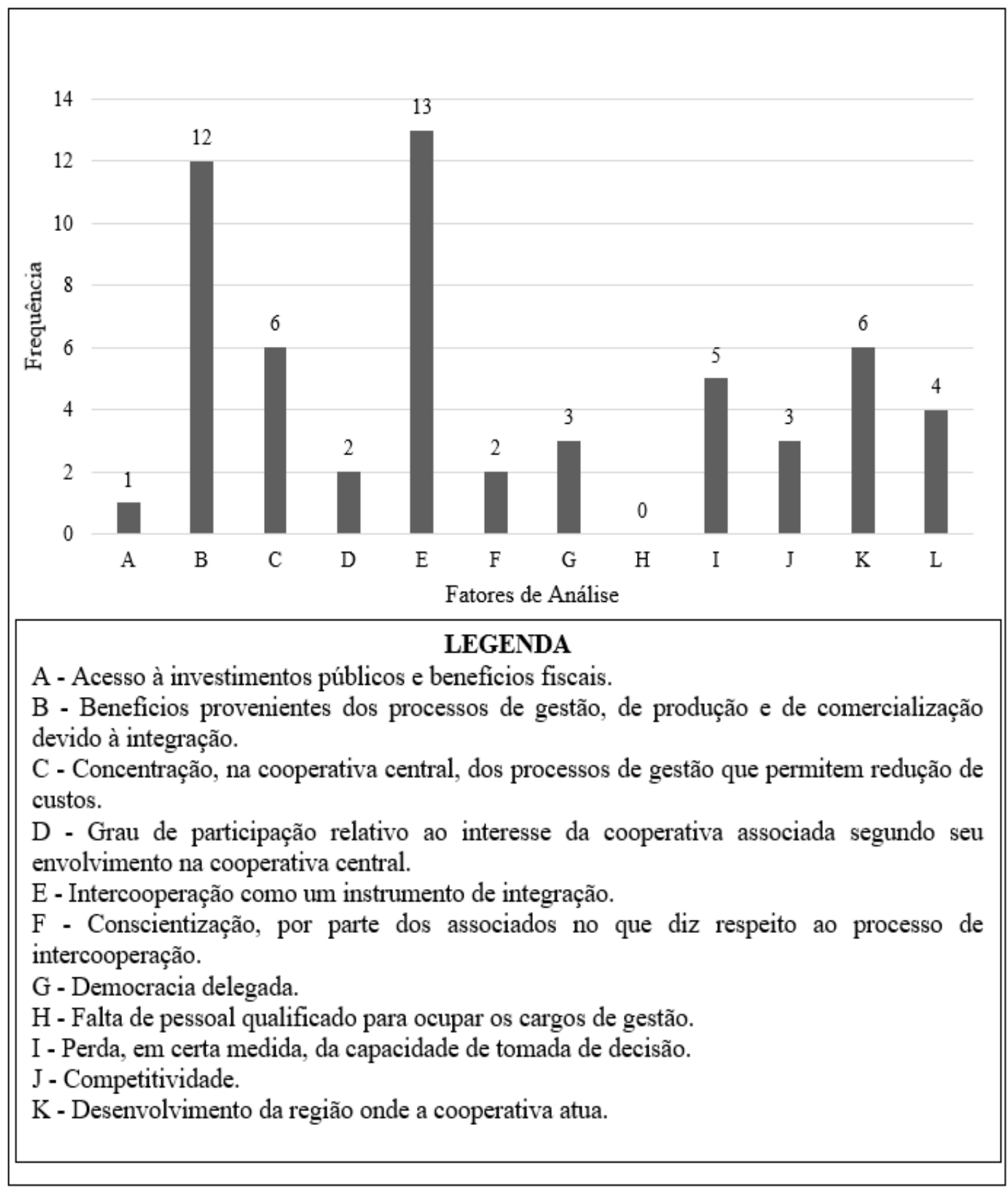

Fonte: dados da pesquisa, 2019.

Diante da Figura 3, pode-se observar que o fator com maior frequência (13 ocorrências) refere-se a intercooperação como um instrumento de integração que fortalece o espírito do cooperativismo. De fato, tanto a entrevista com o executivo da cooperativa singular, quanto a entrevista com o executivo da cooperativa central revelaram que o fortalecimento do espírito cooperativo é fundamental para a continuidade do negócio e para que haja sinergia necessária para os processos de integração e cooperação, como demonstrado pela fala do executivo da cooperativa singular:

"Na verdade assim, a central ela é criada justamente para ser uma força maior. Naquilo que você seria uma Cooperativa sozinha, e teria dificuldade para desenvolver, se busca este conjunto de cooperativas, formar uma força maior. Ter uma forma de fortalecer". 
O executivo da cooperativa central complementa:

O que você quer segurar e [...] nós debatíamos muito isso, a cooperativa vamos dizer... há uma preocupação de manter o seu negócio, se manter sustentável, de manter o homem no campo, da linha sucessória, a herança lá do produtor, quer dizer... tá vindo filho e o filho precisa tocar o negócio e o negócio tem que ser atrativo e rentável, se for, o cara fica no campo, entendeu? Ele não vem pra cidade né? Ele pode ter outras opções de trabalho mas se ganhar dinheiro cara, todo mundo gosta de dinheiro, tá... então é um engenheiro agrônomo, é um médico veterinário, que pode é... é fazer vamos dizer assim, é... filho de um produtor que poderia ir por outro caminho, mas se ele vê viabilidade no negócio do pai é evidente que ele vai ficar lá; e essa é uma preocupação das cooperativas, tem todo um trabalho social, todo um trabalho de desenvolvimento pra fazer essa coisa girar, tá certo?

Nessas duas colocações observam-se fatores relacionados à teoria com respeito a criação da identidade da propriedade rural, do desenvolvimento e da força que o cooperativismo confere a unidade necessária para o desenvolvimento (GIMENES; GIMENES, 2007; POYATOS; GÁMEZ; HERNÂNDEZ, 2010).

Nesse sentido, pode-se observar que a intercooperação demonstra como o processo de integração pode representar a evolução espírito cooperativista podendo apresentar resultados satisfatórios para todas as cooperativas envolvidas no processo. Assim, de forma conjunta, há um fortalecimento do movimento, ao passo que os cooperados passam a ser apoiados de maneira mais efetiva. Nesse contexto, a própria análise documental encontrou, no relatório de gestão da cooperativa singular, estratégias com vistas a proporcionar o desenvolvimento pessoal e profissional da família no agronegócio, o estímulo a sucessão familiar nas propriedades rurais e a permanência do jovem no campo. O que remete a outro princípio importante do cooperativismo que é "Educação, formação e informação" (KONZEN; OLIVEIRA, 2015; OCB, 2018).

A análise de conteúdo revelou também que os benefícios provenientes dos processos de gestão, de produção e de comercialização devido à integração foram apontados pelos entrevistados em 12 excertos. Para o executivo da cooperativa central essa relação é virtuosa e apresenta uma das vantagens:

Mas elas [as cooperativas singulares] estão livres pra operar ... e daí também tem assim, o ponto é assim por exemplo: É... marca única... então vamos imaginar, hoje, a [cooperativa central] é reconhecida por seus produtos, né? Se tivesse cinco fábricas de leite, ia ter cinco marcas, né? Você vai pro outro lado... isso ocorre no frango um pouquinho né? Mas sempre lembrando da escala também... e o tamanho... né? Quando não tem é inviável daí [...] Cinco pequenas indústrias, ou uma indústria grande?

O executivo da cooperativa singular complementa:

Então, por exemplo, a [cooperativa singular] sozinha montar uma, toda uma estrutura de recebimento, processamento e comercialização de leite seria praticamente inviável, porque uma que você precisa de grandes volumes para ser competitivo. Você precisa de muito investimento principalmente para processar e depois você tem um a atuação de logística que é incrível.

Essas contribuições coadunam-se com o apresentado por Poyatos, Gámez e Hernández (2010), ao apontarem que a intercooperação permite uma maior concentração de oferta, a diversificação de produtos e cronogramas, a abertura de novos mercados, a contratação de serviços, 
aquisição de insumos em conjunto, a adoção de novos processos industriais e a melhora nos processos de gestão.

Nesse sentido, as contribuições de Seramim e Miura (2018, p. 147) sobre a autenticidade da marca, apresentadas no estudo realizado com cooperativas na mesma região a que se debruça este estudo, indicam que "as cooperativas exercem forte influência na vida dos consumidores externos e internos, na referência por produtos de qualidade e na presença no dia a dia das pessoas, no âmbito regional", sendo que, estavam incluídos no bojo do estudo, a cooperativa central abordada nesta pesquisa. Assim, pode-se perceber que o fortalecimento da marca da cooperativa central é importante para o processo de venda e distribuição, uma vez que, sozinha em um ambiente altamente competitivo (suinocultura e bovinocultura de leite) a cooperativa singular enfrentaria diversos desafios para consolidação da marca.

Na mesma tônica, os achados de Borges e Domingues (2017) mostraram que em termos de capacidade de produção, crescimento interno, inserção em outros negócios, criação de novas unidades industriais ou parcerias com outras empresas, a intercooperação representa uma estratégia importante para uma cooperativa singular. O estudo demonstra que a parceria proporcionou a diluição dos riscos, custos e benefícios provenientes dos projetos em que essas empresas decidiram investir. Desse modo, a literatura e os achados dessa pesquisa parecem indicar que existem benefícios provenientes dos processos de gestão, de produção e de comercialização devido à integração.

Ainda, com respeito aos benefícios, destaca-se nas entrevistas o fator de análise relativo à concentração, na cooperativa central, dos processos de gestão que permitem redução de custos. Esse fator aparece em terceiro lugar na análise de conteúdo com seis excertos. Um deles pode ser observado na fala do executivo da cooperativa central:

Os stakeholders aí, o pacote dos envolvidos, aqui, é tanto eu como funcionário, como o cara lá como produtor e, finalmente ele é o dono da empresa aqui também, é... a afiliada também tem as suas margens as suas encaminhamentos de custos lá, eu tenho que dividir esse bolo aí de uma forma sistemática que todos ganham tá? As vezes não dá pra fazer, as vezes todos perdem, então vamos amenizar um pouquinho... $\mathrm{E}$ não deixar numa [inaudível], isso, todos perdem menos porque eu divido essa situação e isso fica claro.

Para o executivo da cooperativa singular quando questionado da estrutura de custos das atividades intercooperadas, informa que isso "exigiria muito investimento, muita dedicação aí que é praticamente, se você olhar do ponto de vista de viabilidade econômica e financeira, praticamente eles desaparecem". O que se nota nas duas falas é que a equacionalização dos custos e a consequente diminuição são fatores condicionantes para a intercooperação, de fato, a literatura aponta para a influência positiva no desempenho econômico-financeiro das cooperativas, dadas as proporções (POYATOS; GÁMEZ; HERNÁNDEZ, 2010; KONZEN; OLIVEIRA, 2015; BORGES; DOMINGUES, 2017; MENDES, 2017; SOUZA et al., 2017).

Com respeito as desvantagens a principal desvantagem percebida foi a perda, em certa medida, da capacidade de tomada de decisão. Para o executivo da cooperativa singular esse processo apresenta algumas características:

Tem um conselho que vai reger, vai analisando as questões, vai tomando as decisões, aí você tem de [...] é uma democracia né; é a maioria né; é um processo democrático. Então as vezes até você, poxa vida né, isso poderia ser, poderia ser um pouco diferente por isso ou por aquilo, mas você tem de seguir o que a maioria determina né. Então essa talvez seria a desvantagem de você ter de seguir regras ali. 
Para o executivo da cooperativa central:

Então essa é a equação da administração, que tira o sono dos presidente aqui, que sempre gera um desconforto, que é uma coisa de tá sempre administrando ponto a ponto, tanto é que nessa reunião aqui, mensal, se discute o preço da matéria prima... é estratégico isso, então: qual o custo do suíno? Tanto! Qual é o custo do leite? Tanto! Pra determinar o preço que vai ser remunerado, para o mês. O leite por exemplo é o mês seguinte, o suíno ele vem acompanhando também, o custo de produção, pode ao longo ... você... porque daí eu tenho um ciclo de entrega, aliás, de pagamento de sete em sete dias, já o leite é pagamento mensal. Então o leite eu determino o preço no mês, o suíno pode estar baixando o preço, subindo o preço e ir remunerando conforme a entrada.

Figura 4 - Mapa Relacional dos Fatores de Análise

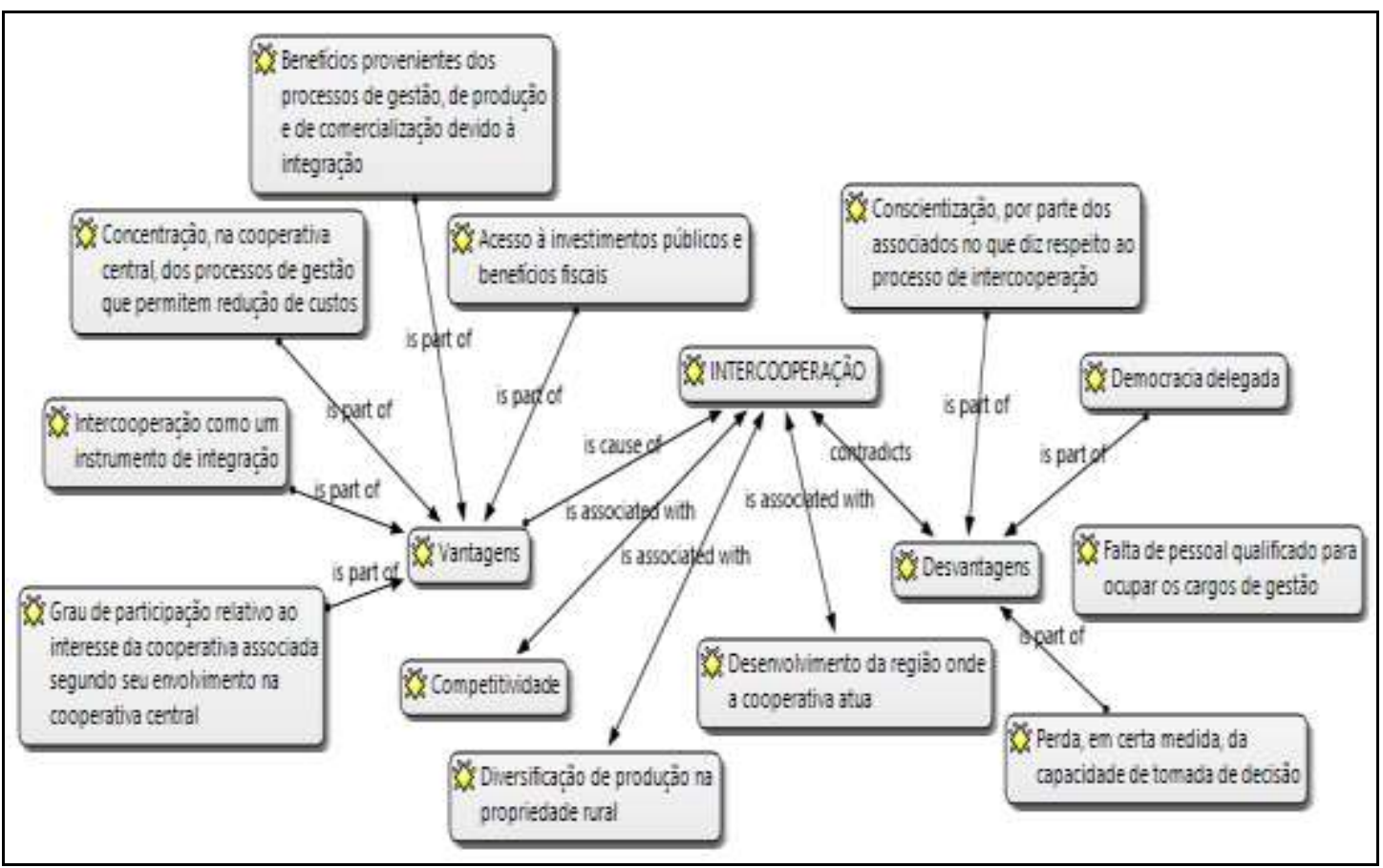

Fonte: elaborado pelos autores com base em dados da pesquisa utilizando o Atlas.Ti, 2019.

Além disso, o executivo da cooperativa central se questiona sobre como remunerar o fornecedor que ao mesmo tempo é o dono da cooperativa. Equacionar os custos realmente é um grande desafio como demonstrado na pesquisa de Mateos-Ronco e Guzmán-Asunción (2018) com respeito ao papel que o associado na influência de políticas que maximizam os preços recebidos pelos membros em detrimento do autofinanciamento da entidade. Por outro lado, a tomada de decisão colegiada envolve os desafios naturais do processo democrático (democracia delegada). Entretanto, a participação representa um ponto nevrálgico nas instâncias de decisão no modelo cooperativista de ser empresa (BIALOSKORSKI NETO, 2004; 2007; FORCADELL, 2005; POYATOS; GÁMEZ; HERNÁNDEZ, 2010).

Considerando a participação, outro fator relevante apontado pelos achados da pesquisa diz respeito ao grau de participação relativo ao interesse da cooperativa associada segundo seu envolvimento na cooperativa central, apresentando dois excertos na análise de conteúdo. Segundo os entrevistados, a gestão profissional, associada a participação quase que equilibrada entre as associadas permitem que haja um interesse harmônico entre os atores envolvidos. Ademais, o conselho de administração é formado pelos presidentes das cooperativas singulares, o que também 
permite equacionar os interesses. Embora a literatura indique que quanto maior o grau de participação, maior o grau de interesse (BIALOSKORSKI NETO, 2004; 2007; FORCADELL, 2005; POYATOS; GÁMEZ; HERNÁNDEZ, 2010; MENDINA, 2015), cabe destacar que para a cooperativa central em estudo o grau de participação das associadas é relativamente equitativo dada a composição do capital social. No entanto, cabe destacar que as outras cooperativas singulares envolvidas no processo não foram pesquisadas.

As desvantagens relacionadas à falta de pessoal qualificado não foram identificadas, sendo que, o executivo da cooperativa singular informou que sempre existem políticas para a formação de executivos, o que é corroborado nos gastos com treinamentos descritos nos relatórios anuais. Emergiram das análises três fatores como vantagens relacionadas à competitividade, à diversificação da produção na propriedade rural e o desenvolvimento da região onde a cooperativa atua. Embora esses fatores não tenham sido delineados diretamente nos achados de Poyatos, Gámez e Hernández (2010), são apoiados pela literatura (FORCADELL, 2005; GIMENES; GIMENES, 2007; LAGO; SILVA, 2012; ALFONSO; CUMPLIDO; GONZALEZ, 2016; BORGES; DOMINGUES, 2017; MATEOS-RONCO; GUZMÁN-ASUNCIÓN, 2018; SALVADOR; SANZ; CASTEL, 2018; SERAMIM; MIURA, 2018).

\section{Considerações finais}

A pergunta que motivou esta pesquisa tangenciou os benefícios, desafios e perspectivas oferecidos pelo processo de intercooperação. Em linhas gerais, os achados coadunam-se com o framework proposto por Poyatos, Gámez e Hernández (2010), indicando que a intercooperação como um instrumento de integração fortalece o espírito do cooperativismo, que existe um grau de participação relativo ao interesse da cooperativa associada segundo seu envolvimento na cooperativa central, que existem benefícios provenientes dos processos de gestão, de produção e de comercialização devido à integração, que há uma concentração, na cooperativa central, dos processos de gestão que permitem redução de custos e que há acesso à investimentos públicos e benefícios fiscais. As desvantagens apresentadas pelo frame também puderam ser observadas, quais sejam, a perda, em certa medida, da capacidade de tomada de decisão (autonomia), a democracia delegada, pois, o associado à cooperativa singular não toma decisões diretas relativas aos processos de gestão da cooperativa central, a conscientização, por parte dos associados no que diz respeito ao processo de intercooperação.

O fator falta de pessoal qualificado para ocupar os cargos de gestão não foi constatado nas respostas dos entrevistados, uma vez que, como as duas cooperativas encontram-se como organizações de expressivo faturamento, a gerência profissional tenha ganhado espaço. Outro fator relevante, observado nos relatórios anuais de ambas cooperativas, é que existe uma grande preocupação com capacitação e treinamento.

Os fatores que emergiram da análise indicam que o processo de intercooperação permite que a atividade torne-se mais competitiva, que se diversifique a produção rural na propriedade do associado e, por fim, haja o desenvolvimento da região onde a cooperativa se instala, oferecendo mais perspectivas para o homem do campo e sua família, bem como, para as rodas da sociedade circunvizinhas.

Aglutinando-se os dados apresentados na pesquisa documental e nas análises das entrevistas no que diz respeito às perspectivas, o ambiente institucional onde as cooperativas estão inseridas é um dos grandes desafios a serem enfrentados mais especificamente em termos de instabilidade política, taxa de juros, aumento de impostos e câmbio. Ainda assim, a cooperativa central tem um plano de expansão até 2030 para tornar-se a cooperativa que mais abate suínos na América Latina ( 15 mil cabeças dia).

Desse modo, o presente estudo atingiu seu objetivo de compreender em que se constituem as vantagens e desvantagens da intercooperação entre uma cooperativa central e singular. Cabe 
destacar, também, que os achados de Poyatos, Gámez e Hernández (2010) estão diretamente associados ao cooperativismo no contexto europeu. Isso pode justificar as diferenças nos achados, bem como, os fatores emergentes da análise, o que complementa o frame proposto e representa uma contribuição do estudo. De todo modo, a principal contribuição do estudo repousa na análise da relação entre uma cooperativa central e sua singular no contexto do agronegócio brasileiro. $\mathrm{O}$ estudo contribui também com a escassa literatura sobre o tema, muito embora, as cooperativas representem um papel importante para o setor e para economia do país. Além disso, o estudo pode contribuir para meta-análises sobre o tema, comparando diversos achados de diversos contextos e atividades.

Como principal limitação, a pesquisa não atingiu as demais cooperativas associadas que formam a cooperativa central nem, tampouco, investigou as relações existentes entre as cooperativas singulares e os seus cooperados nas propriedades rurais.

Para estudos futuros, recomenda-se que todas as cinco cooperativas envolvidas no processo de intercooperação sejam estudadas, bem como, que seja realizada uma comparação, sob o mesmo prisma, com uma cooperativa que não está inserida em um processo de intercooperação.

\section{Referências}

ALFONSO, C. G.; CUMPLIDO, F. J. S.; GONZALEZ, M. O. B.. Cooperativism, entrepreneurship and economic development: a linking theoretical model/Cooperativismo, factor empresarial y desarrollo económico: propuesta de un modelo teórico de enlace. REVESCO. Revista de Estudios Cooperativos, n. 122, p. 110-135, 2016. Disponível em: dx.doi.org/10.5209/rev_REVE.2016.v122.52018. Acesso em: 08 jun. 2019.

BARDIN, L. Análise de conteúdo. São Paulo: Edições 70, 2016.

BIALOSKORSKI NETO, S. Economia das organizações cooperativas: uma análise da influência da cultura e das instituições. 2004. 178f. (Livre Docência em Economia das Organizações) Faculdade de Economia, Administração e Contabilidade de Ribeirão Preto, Universidade de São Paulo, Ribeirão Preto, 2004.

BIALOSKORSKI NETO, S. Um ensaio sobre desempenho econômico e participação em cooperativas agropecuárias. Revista de Economia e Sociologia Rural, v. 45, n. 1, p. 119-138, 2007. Disponível em: http://dx.doi.org/10.1590/So103-20032007000100006. Acesso em: o8 set. 2018.

BORGES, G. M.; DOMINGUES, C. R. Estratégias de Crescimento de Cooperativas Agrícolas e Agropecuárias: Estudo de Casos Comparados da Região do Triângulo Mineiro/MG e dos Campos Gerais/PR. Organizações Rurais \& Agroindustriais, v. 19, n. 1, p. 8-22, 2017.

CARPES, A. M.; SCHERER, F. L.; CARVALHO, B. M.; CARPES, G. M.; BEURON, T. A. Análise dos consórcios de exportação como ferramenta estratégica para a obtenção de inovações às empresas integrantes. RACE: Revista de Administração, Contabilidade e Economia, v. 12, n. 1, p. o-o, 2013.

COOPER, D. R.; SCHINDLER, P. S. Métodos de pesquisa em administração. 10. ed. Porto Alegre: Bookman, 2011.

DAL-SOTO, F.; MONTICELLI, J. M. Coopetition Strategies in the Brazilian Higher Education. Revista de Administração de Empresas, v. 57, n. 1, p. 65-78, 2017.

FORCADELL, F. J. Democracy, cooperation and business success: the case of Mondragón Corporación Cooperativa. Journal of Business Ethics, v. 56, n. 3, p. 255-274, 2005. Disponível em: https://doi.org/10.1007/s10551-004-5094-5. Acesso em: o8 set. 2018. 
GIL, A. C. Métodos e técnicas de pesquisa social. 6. ed. São Paulo: Atlas, 2008.

GIMENES, R. M. T.; GIMENES, F. M. P. Agronegócio cooperativo: a transição e os desafios da competitividade. Revista Cadernos de Economia, v. 11, n. 20, p. 45-72, 2007.

HENRIQUES, F. E.; MIGUEL, P. A. C. Use of product and production modularity in the automotive industry: a comparative analysis of vehicles developed with the involvement of Brazilian engineering centers. Gestão \& Produção, v. 24, n. 1, p. 161-177, 2017.

KONZEN, R. R. P.; OLIVEIRA, C. A. O. Intercooperação entre cooperativas: barreiras e desafios a serem superados. Revista de Gestão e Organizações Cooperativas, v. 2, n. 4, p. 45-58, 2015. Disponível em: dx.doi.org/10.5902/2359043220410. Acesso em: o8 set. 2018.

LAGO, A.; SILVA, T. N. Condicionantes do desenvolvimento de relacionamentos intercooperativos no cooperativismo agropecuário. Organizações Rurais \& Agroindustriais, v. 14, n. 2, p. 212-226, 2012.

LIMA, G. B.; CARVALHO, D. T. Evolução dos consórcios de exportação no Brasil (2002-2008): um estudo exploratório. Revista de Gestão, v. 19, n. 2, p. 183-200, 2012.

OCB. Organização das Cooperativas Brasileiras. O que é o cooperativismo. Disponível em: www.ocb.org.br/o-que-e-cooperativismo. Acesso em: o8 set. 2018.

MATEOS-RONCO, A.; GUZMÁN-ASUNCIÓN, S. Determinants of financing decisions and management implications: evidence from Spanish agricultural cooperatives. International Food and Agribusiness Management Review, v. 21, n. 6, p. 701-721, 2018.

MENDES, F. J. A influência da intercooperação no desempenho econômico-financeiro em cooperativas agroindustriais dos campos gerais. 2017. 114f. Dissertação (Mestrado Profissional em Gestão de Cooperativas) - Programa de Pós-Graduação em Gestão de Cooperativas, Pontifícia Universidade Católica do Paraná (PUC-PR), Curitiba, 2017. Disponível em www.ocepar.org.br/ocepar/UPL/Acervo/Disserta\%C3\%A7\%C3\%A3o_Fernando\%20Jos\%C3\%A9\%20 Mendes.pdf. Acesso em: 22 abr. 2019.

MENDINA, H. J. C. Proposta de framework para a intercooperação entre cooperativas agroalimentares atuando em rede horizontal. 2015. 283f. Tese (Programa de Pós-Graduação em Administração) Unidade Acadêmica de Pesquisa e Pós-Graduação, Universidade do Vale do Rio dos Sinos UNISINOS, São $\quad$ Leopoldo, $2015 . \quad$ Disponível http://www.repositorio.jesuita.org.br/handle/UNISINOS/4857. Acesso em: 22 abr. 2019.

MENDINA, H. J. C.; ANTUNES JUNIOR, J. A.V.; LIMA, J. J. M.; TIBURSKI, E. F. Fatores impulsionadores e restritivos à intercooperação em redes cooperativas agroalimentares: estudo de caso malsucedido de rede do RS. In: II Fórum Internacional Conecta PPGA, Santa Maria, 2017. Anais. Santa Maria: Conecta PPGA, 2016. Disponível em: even3.azureedge.net/anais/6238o.pdf. Acesso em: o8 set. 2018.

MINISTÉRIO DA AGRICULTURA. Cooperativismo no Brasil. Disponível em: www.agricultura.gov.br/assuntos/cooperativismo-associativismo/cooperativismo-brasil. Acesso em: o8 set. 2018.

PERONI, N. D.; PEGLOW, K.; KOHLER, R. Intercooperação: estratégia para o desenvolvimento rural sustentável e promoção da segurança alimentar no Território Zona Sul (RS). Natural Resources, v. 8, n. 2, p. 1-10, 2018. Disponível em: doi.org/10.60o8/CBPC2237-9290.2018.002.0001. Acesso em: o8 ago. 2019. 
POYATOS, R. P.; GÁMEZ, M. M. V.; HERNÁNDEZ, J. V. Las sociedades cooperativas de segundo grado como instrumento de cooperación entre cooperativas: aspectos económicos y organizativos. Revista de Estudios Empresariales, n. 1, 2010. Disponível em: revistaselectronicas.ujaen.es/index.php/REE/article/view/411. Acesso em: o8 set. 2018.

SALVADOR, M. L. E.; SANZ, F. J. P.; CASTEL, A. G. Áreas rurales y cooperativas: iniciativas de mujeres para el desarrollo. REVESCO: Revista de estudios cooperativos, n. 127, p. 116-138, 2018. Disponível em: 10.5209/REVE. 58397. Acesso em: o8 jun. 2019.

SERAMIM, R. J.; MIURA, M. N. A autenticidade da marca e as cooperativas agroalimentares do Paraná. Revista de Gestão e Organizações Cooperativas, v. 5, n. 9, p. 147-162, 2018. Disponível em: $10.5902 / 2359043228743$. Acesso em: o8 set. 2018.

SILVA, C. R. R.; LEISMANN, E. L. Análise da percepção dos envolvidos sobre a sustentabilidade ambiental da soja no Oeste do Paraná. Revista Competitividade e Sustentabilidade, v. 3, n. 1, p. 110, 2016. Disponível em: doi.org/10.5935/2359-5876.201600o1. Acesso em: o8 set. 2018.

SILVA, E. L.; MENEZES, E. M. Metodologia da pesquisa e elaboração de dissertação. 4a. ed. Florianópolis: UFSC, 2005.

SOUZA, H. R. S.; WILHELM, E. M. S.; BRANDALISE, L. T.; RIBEIRO; I. Internacionalização de cooperativas por meio da intercooperação. Revista Estudo \& Debate, v. 24, n. 2, p.192-2010, 2017. Disponível em: dx.doi.org/10.22410/issn.1983-036X.v24i2a2017.1303. Acesso em: o8 set. 2018.

THAMER, R.; LAZZARINI, S. G. Projetos de parceria público-privada: fatores que influenciam o avanço dessas iniciativas. Revista de Administração Pública, v. 49, n. 4, p. 819-846, 2015. 